\title{
Quantitative trait loci mapping for vegetative propagation in pedunculate oak
}

\author{
Caroline Scotti-SAintagne, Evangelista Bertocchi, Teresa BARreneche, Antoine Kremer, \\ Christophe PLOMION*
}

UMR 1202 BIOGECO, INRA, Équipe de Génétique, 69 route d’Arcachon, 33612 Cestas Cedex, France

(Received 23 September 2004; accepted 12 October 2004)

\begin{abstract}
Vegetative propagation is one of the main methods used for the deployment of improved genetic forest tree species. The objective of this paper was to study the genetic architecture of vegetative propagation by detecting Quantitative Trait Loci (QTL) in pedunculate oak (Quercus robur). The mapping population consisted on an $\mathrm{F}_{1}$ family of 278 offspring. Assessment of rooting ability over three years permitted the detection of 10 QTLs explaining between 4.4 and $13.8 \%$ of phenotypic variance, of which the two strongest were stable across years. Ongoing genomics programs in trees and in Arabidopsis are starting to shed light on the nature of the underlying genes.
\end{abstract}

vegetative propagation / QTL / Quercus robur

Résumé - Détection de locus à effet quantitatif qui contrôlent l'aptitude au bouturage chez le chêne pédonculé. La multiplication végétative est une des principales méthodes utilisée pour l'exploitation du matériel forestier amélioré. L'objectif de cet article était d'étudier l'architecture génétique de la propagation végétative en détectant des QTL chez le chêne pédonculé (Quercus robur). La population de cartographie consistait en une famille $\mathrm{F}_{1}$ de 278 descendants. La mesure de l'aptitude à l'enracinement durant quatre années a permis de détecter 10 QTL expliquant entre 4,4 et 13,8\% de la variance phénotypique, les deux plus forts étant stables à travers les années. L'avancée des programmes de génomique chez les arbres et chez Arabidopsis permettra de déterminer la nature des gènes sous-jacents.

multiplication végétative / QTL / Quercus robur

\section{INTRODUCTION}

Most traits in forest trees do not display a discrete distribution but result from the collective action of multiple genes which exhibit, in segregating populations, quantitative variation. Up to 1980, most studies on the genetic basis of quantitative traits considered only the aggregate effects of all the genes causing the variation [14]. In the 1980s, two developments made it possible to study the individual genes controlling quantitative traits, known as Quantitative Trait Loci or QTL [16]. On the one hand, the advance of DNA marker-based technologies allowed the construction of genetic linkage maps, covering the entire genome of many forest tree species [10]. On the other hand, the development of dedicated statistical methods allowed to link polymorphism in molecular markers with the phenotypic variation of the quantitative traits [9]. Analysis of variance and interval mapping approaches have been widely used by forest geneticists [28] but the limited size of forest tree segregating populations has often led to an over-estimation of QTL effects (the so called Beavis effect, [1]) and contributed to the large confidence intervals associated with QTL locations. More recently, statistical approaches have been developed to increase the statistical power of QTL detection and have received increasing attention in QTL experiments [7, 27]. One of theses approaches is the composite interval mapping developed by Zeng [31] and Jansen and Stam [21], which combines interval mapping with multiple regression. Like simple interval mapping, this method evaluates the possibility of a target QTL at multiple analysis points across each interlocus interval. Moreover, at each point it also includes in the analysis the effect of one or more markers elsewhere in the genome. Besides these statistical procedures, it has been clearly shown that the power of QTL detection largely depends on quality of the phenotypic assessment. Without the possibility of developing F3 populations or even recombinant inbred lines to precisely estimate the value of the traits, clonally propagated material has became the material of choice for forest tree geneticists [6, 27].

Vegetative propagation ability varies between and within species, and even within an individual, depending upon life stage [20]. Very few QTL studies have made used of vegetatively

* Corresponding author: christophe.plomion@pierroton.inra.fr 
propagated material: in poplar for bud phenology [15], in Salix for growth [29] and in oak for leaf morphology [27]. Benefits of vegetatively propagated material include the possibility of detecting QTL $\times$ environment interactions and to perform destructive testing of individual ramets for wood quality, biomass, or disease resistance assessment, without loss of the genotype [6].

Considering the importance of vegetative propagation in the breeding programs of some major tree species (e.g. Eucalyptus, Populus, Salix, Cryptomeria), several investigations have been conducted to understand the genetic basis of this trait. In Eucalyptus the heritability for vegetative-propagation traits was found to be moderate $\left(h^{2}=0.4\right)$ [4]. The genetic architecture of adventitious rooting ability has been shown to be controlled by a relatively small number of major-effect QTL [18]. Similarly, in poplar, the heritability for in vitro adventitious root regeneration was found to be very high (0.72) and controlled by a major QTL explaining $37 \%$ of the phenotypic variance [19]. In addition to a strong genetic control of adventitious rooting ability, QTLs were found to be stable across environments. Out of the 9 QTLs detected in Eucalyptus by Marques et al. [24], five were found to be stable over two consecutive years.

The purpose of the present work was to investigate the genetic basis of vegetative propagation ability in pedunculate oak (Quercus robur L.). QTL detection was performed in an $\mathrm{F}_{1}$ family. The assessment during four years made it possible to study QTL stability over time.

\section{MATERIALS AND METHODS}

\subsection{Plant material}

A full-sib family of Quercus robur (278 individuals) was established in the field as mother stock plants as described in Saintagne et al. [27]. Since the age of five years, each stool-bed was hedged yearly at the level of the ground in late-February. In late April, when sprouts were fully elongated, cuttings were prepared for vegetative propagation. The cuttings consisted of stem segments about 10 to $12 \mathrm{~cm}$ long, comprising at least two internodes. On average about 20 cuttings were used for propagation of each stool bed. They were dipped in a rooting hormone (Rhipozon AA 0.5 ) and transplanted in $80 \mathrm{~cm}^{3}$ containers with a 60/40 mixture of peat/ perlite. The cuttings were then transferred to a fog system-watered greenhouse. The first rooting occurred after five weeks, and more than $60 \%$ of the cuttings rooted within two months. The rooted cuttings were further transplanted into $4 \mathrm{~L}$ containers (with a mixture of 2/1/2: peat/sand/pine bark) in September. They over-wintered in a greenhouse and grew outdoors in the nursery for an additional year. The procedure for vegetative propagation was used recurrently over four successive years from 1997 to 2000 on 232 offspring among the 278 . The measurements were as percent cuttings able to root (Cutt).

\subsection{Data analysis}

A map was constructed for each parent of the cross following the so called double-pseudo-testcross mapping strategy [17] as previously described in Saintagne et al. [27]. The data originated from 128 markers recorded on each of the 278 full sibs and evenly distributed throughout the genome. The female framework map was composed of 75 markers and covered a distance of $902 \mathrm{cM}$, with an average spacing between markers of $14 \mathrm{cM}$. The male framework map comprised 72 markers over a total distance of $933 \mathrm{cM}$, with an average marker spacing of $15.5 \mathrm{cM}$. QTL detection was done separately for each parental map. We used the Composite Interval Mapping method [21], implemented in the MultiQtl software ([8]; http://esti.haifa.ac.il/ p poptheor), to detect QTL and estimate their phenotypic effect [31]. Standard deviation was estimated for each QTL position by bootstrap with 1000 resamplings. Empirical statistical significance thresholds for declaring the presence of a QTL was determined by permutation (1000 replicates) of the data set [11]. Since the permutation tests were performed separately on each chromosome, we further computed the corresponding Type I error rate at the whole genome level as explained in Saintagne et al. [27]. Epistatic interactions between pairs of markers were investigated by a two-factor analysis of variance using the $Q$ gene software (http://www.qgene.org/). The detection threshold for epistatic effect was fixed at 0.01 for the $\mathrm{N}$ tests, corresponding to a probability of 0.0001 for a single test using the Bonferroni correction. Graphs of linkage maps and QTL were drawn using the MapChart software version 2.0 [30]

\subsection{Statistical significance of colocalisation between QTL detected in two different years}

To exclude that the overlap of QTL in two different years was due by chance alone, we calculated the probability of the observed distribution of QTL in two different years under the null hypothesis of random distribution [22]. To do so, the genome was subdivided into $\mathrm{N}$ intervals. Interval size corresponds to the mean distance between the position of the highest LOD score from the composite interval mapping (P1) and the position of the mean value for maximum LOD score after bootstrap analysis (P2). If $\mathrm{L}$ is the number of QTLs in a given year exhibiting the largest number of QTLs, $S$ the number of QTLs in an other year, and $M$ the number of QTLs shared by the two years, then the probability of having $\mathrm{M}$ intervals in common between the two years is given by the following ratio of combinations:

$$
\text { Pvalue }=\frac{C_{L}^{M} \times C_{L}^{S-M}}{C_{N}^{S}} .
$$

On average the distance between P1 and P2 was $7 \mathrm{cM}$. Since the length of the female map and male were $902 \mathrm{cM}$ and $933 \mathrm{cM}$, the number of intervals which were compared was 129 and 133 in the female and male maps, respectively.

\section{RESULTS AND DISCUSSION}

\subsection{Phenotypic variation}

The frequency distribution of vegetative propagation ability (Cutt) is presented in Figure 1. Only measurements realised in 1998 were normally distributed, as shown by the Box and Cox method [5]. A square root transformation was applied to normalize the data for the other measurements.

Due to the difficulty to vegetatively propagate adult plant material, ability for vegetative propagation had not been recorded on the parents. On average, $40 \%$ of the cuttings rooted over the four years (Tab. I). The coefficient of phenotypic variation was 0.67 (averaged over the four years) with the strongest value in 2000 (0.92). A significant year effect, as tested by a one way ANOVA (data not shown) was detected, indicating a significant environment effect on the ability to vegetative propagation. Absence of replicates within year of assessment did not permit to calculate repeatability (within family heritability), neither to test the clone $\times$ year interaction. However, the highly 

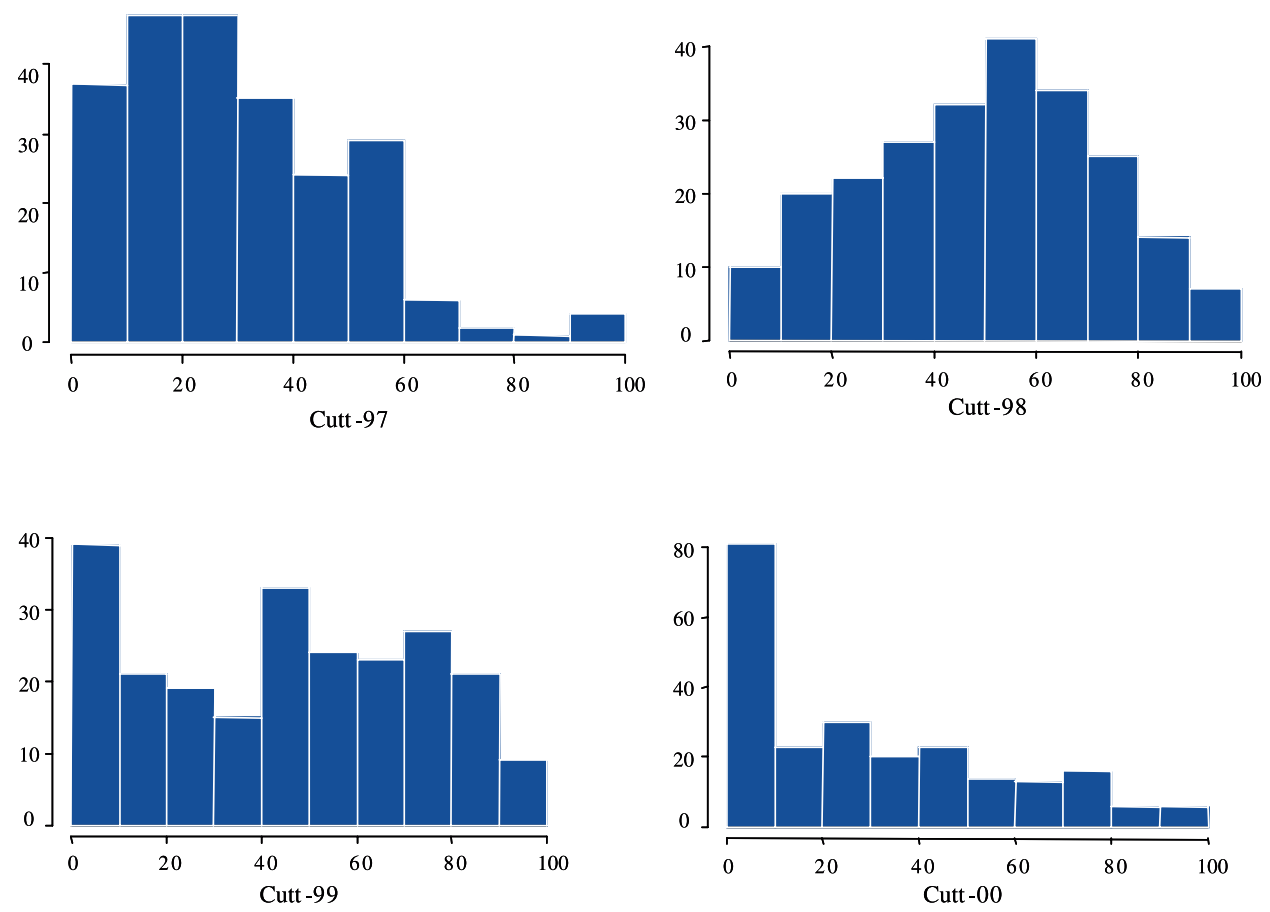

Figure 1. Frequency distribution for vegetative propagation. On the $\mathrm{x}$ axis is represented the percent of cutting that rooted, and on the $y$ axis the number of individuals.

Table I. Mean and coefficient of phenotypic variation for percentage of rooting (cutt).

\begin{tabular}{lcccc}
\hline Year & 1997 & 1998 & 1999 & 2000 \\
\hline Mean & 30.41 & 51.73 & 45.78 & 30.06 \\
Standard deviation & 20.61 & 22.94 & 28.43 & 27.51 \\
CV $_{P}$ & 0.68 & 0.45 & 0.62 & 0.92 \\
\hline
\end{tabular}

variable phenotypic correlations among pair of years (Tab. II) suggest the presence of clone $\times$ year interaction. In other words, the clone classification could vary between years. Notably, phenotypic correlations were very weak between the first year of measurement (1997) and the following years (1998, 1999, 2000). As a result, QTL detection was performed on each year separately rather than on the mean values.

\subsection{QTL detection}

Ten QTLs significant at 5\% at the genome level were detected (Tab. III). If we consider as the same QTL those detected on the same region during several years, this number drops down to 6 putatively unique QTLs (Fig. 2). The percent of phenotypic variance explained by each QTL was small to moderate, varying from 4.3 to $13.8 \%$ (Tab. III). Again, absence of replicates did not allow estimation of QTL genetic effect. However, taking into account the weak to moderate interannual correlations it could be assume a strong environment effect and a weak heritability for this trait. Consequently the part of genetic variation explained by each QTL could be very
Table II. Pearson correlations coefficient for percentage of rooting (cutt) over 4 successive years. Values indicated in bold are significant at the $5 \%$ level.

\begin{tabular}{lccc}
\hline & 1997 & 1998 & 1999 \\
\hline 1998 & $\mathbf{0 . 1 9}$ & & \\
1999 & $\mathbf{0 . 1 4}$ & $\mathbf{0 . 3 6}$ & \\
2000 & 0.099 & $\mathbf{0 . 3 7}$ & $\mathbf{0 . 5 8}$ \\
\hline
\end{tabular}

high. The number of QTLs detected per year varied from zero in 1997 to 4 in 1998. No epistatic effect was detected between pairs of markers for any of the four years of assessment. Among the 10 QTLs, 3 were specific to year 1998 (LG1m, 3m and 7f). The other 7 QTLs were detected on the male map across at least two years (LG6m and LG8m), with one being found for three years on LG12m. The coincidence between the QTLs detected on LG6m, LG8m LG12m in 1999 and 2000 was highly significant $\left(P=2.6 \times 10^{-6}\right)$, indicating that the genetic control of vegetative propagation was not disrupted by environmental variation in these particular genomic regions. The discrepancy between the detection of stable QTLs across years on the one hand, and the weak inter-annual phenotypic correlation on the other hand, could be explained by the cumulated effect of yearspecific QTLs displaying a too small phenotypic effect to be detected in the oak progeny. Stable QTLs across years have been already found in Eucalyptus by Marques et al. [24]. These authors identified 9 QTLs explaining between 2.79 and $8.11 \%$ of the phenotypic variance of rooting ability, with 5 being detected in two consecutive years and 4 being specific to only one year. In maritime pine (C. Plomion, unpublished data), only 
LG1M

LG3M

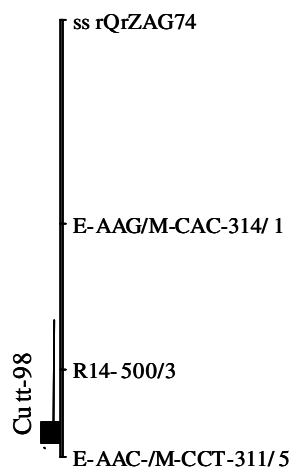

LG6M

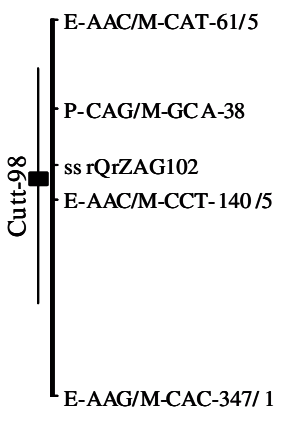

LG7F

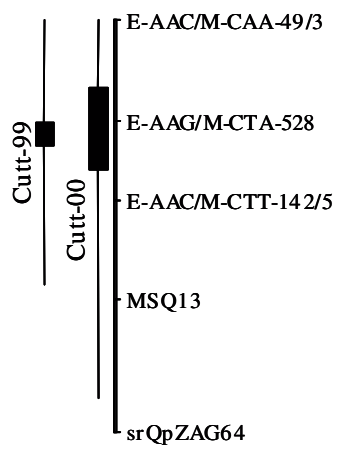

LG8M

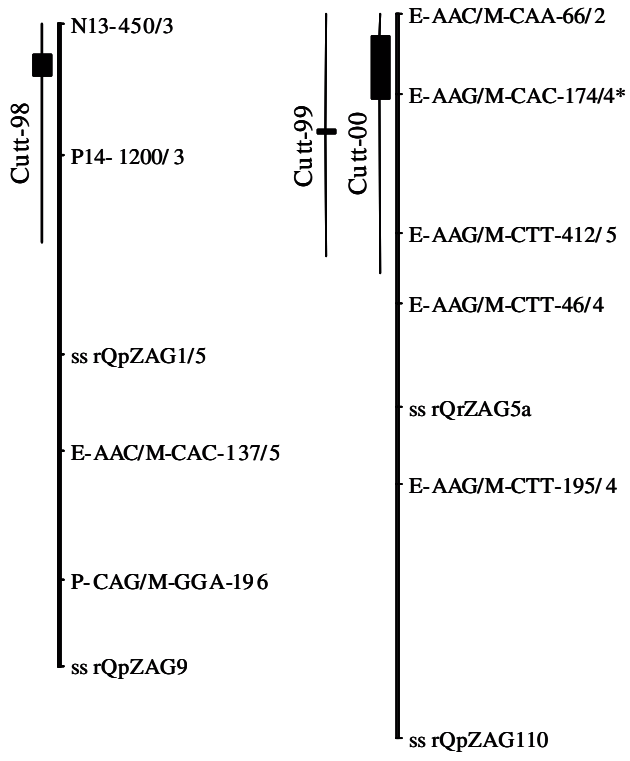

LG12M

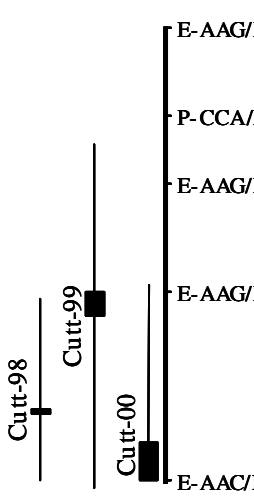

Figure 2. Location of significant QTLs for ability to vegetative propagation (Cutt). Each QTL is delineated by the position of the highest LOD score and value of the highest LOD score. The confidence interval of its position is based on 1000 bootstrap samples and indicated as a line. 
Table III. QTL detection parameters. LG, linkage group ( $\mathrm{m}=$ male, $\mathrm{f}=$ female); $N$, number of individuals genotyped for the flanking markers; Lod, highest LOD in the interval; $\alpha_{c h r}$, type I error at the chromosome level obtained from 1000 permutations tests; $\alpha_{\text {gen }}$, type I error at the genome level; PEV, percentage of phenotypic variance explained by the QTL; P1, position (in cM) relative to the top of the LG of the highest LOD score from the Composite Interval Mapping; P2, position of the mean value for maximum LOD score after bootstrap analysis (1000 bootstrap samples); CI, QTL confidence interval (95\%) based on the 1000 bootstrap samples.

\begin{tabular}{lccccccccc}
\hline Trait & LG & $N$ & Lod & $\alpha_{\text {chr }}$ & $\alpha_{\text {gen }}$ & PEV & $P_{1}$ & $P_{2}$ & CI \\
\hline Cutt-98 & $7 \mathrm{f}$ & 138 & 3.0 & 0.002 & 5 & 10.6 & 87.6 & 84.9 & 24.1 \\
Cutt-98 & $1 \mathrm{~m}$ & 148 & 2.7 & 0.002 & 5 & 6.4 & 61.6 & 58.6 & 15.4 \\
Cutt-98 & $3 \mathrm{~m}$ & 213 & 2.7 & 0.002 & 5 & 4.3 & 22.1 & 23.8 & 16.8 \\
Cutt-98 & $12 \mathrm{~m}$ & 196 & 4.1 & 0.001 & 5 & 9.9 & 55.6 & 54.9 & 15.9 \\
Cutt-99 & $6 \mathrm{~m}$ & 199 & 5.0 & 0.001 & 5 & 8.9 & 14.8 & 18.0 & 20.0 \\
Cutt-99 & $8 \mathrm{~m}$ & 179 & 4.8 & 0.001 & 5 & 10.7 & 17.3 & 16.7 & 18.4 \\
Cutt-99 & $12 \mathrm{~m}$ & 175 & 3.0 & 0.002 & 5 & 5.5 & 38.1 & 41.6 & 24.7 \\
Cutt-00 & $6 \mathrm{~m}$ & 185 & 3.2 & 0.001 & 5 & 6.6 & 9.8 & 21.5 \\
Cutt-00 & $8 \mathrm{~m}$ & 173 & 6.2 & 0.001 & 5 & 13.8 & 3.3 & 32.9 \\
Cutt-00 & $12 \mathrm{~m}$ & 196 & 5.0 & 0.001 & 5 & 8.8 & 65.3 & 59.8 & 22.7 \\
\hline
\end{tabular}

one strong QTL was detected on linkage group 6 of the map described by Plomion et al. [25, 26], explaining a high percentage $(18.7 \%)$ of the phenotypic variance.

\subsection{Molecular basis of adventitious root formation}

Adventitious root formation is an essential step in the vegetative propagation of plants. It is a complex process, which is affected by multiple factors including levels of growth regulators [23] and of phenolic compounds [12], nutritional status, associated stress responses such as wounding, and genetic characteristics. In oak the ability for vegetative propagation was found to be controlled by at least 6 unique QTLs, collectively explaining $53.9 \%$ of the phenotypic variation; two individual QTLs explaining more than $10 \%$ of the phenotypic variance were found over consecutive years. This result agrees with results obtained in forest tree species so far, and support the oligogenic nature of adventitious rooting, where few QTLs control a major part of phenotypic variance. The mechanisms by which adventitious roots are formed are not known in trees but recent results obtained in the model plant species Arabidopsis thaliana have started to shed light on the underlying molecular mechanisms. In particular, three mutants have been identified, that are altered in their aptitude to form adventitious roots. Two mutants correspond to auxin over-producers [2, 13] surl and sur2. In particular surl behaves like a "hairy root" induced by Agrobacterium rhizogenes, as it spontaneously produces adventitious roots from different organs. A third mutant "argonaute" (agol) [3], is unable to develop adventitious roots from the hypocotyl or other aerial organs in response to auxin, whereas roots respond normally.

These genes are already mapped in the genome of Arabidopsis; their sequences may represent the basis for a "candidate gene" approach in pine and oak, and lead to the identification of the genes involved in the control of rooting ability in trees; mapping of these genes will possibly help to unveil the role and molecular function of the detected QTLs.

\section{REFERENCES}

[1] Beavis W.D., The power and deceit of QTL experiments: lessons from comparative studies, in: Proceedings of the 49th annual corn and sorghum industry research conference, Chicago, IL, 1995, pp. 250-266.

[2] Boerjan W., Cervera M.T., Delarue M., Beekman T., Dewitte W., Bellini C., Caboche M., Van Onckelen H., Van Montagu M., Inzé D., SUPER ROOT, a recessive mutation in Arabidopsis, confers auxin overproduction, Plant Cell 7 (1995) 1405-1419.

[3] Bohmert K., Camus I., Bellini C., Bouchez D., Caboche M., Benning C., AGO1 defines a novel locus of Arabidopsis controlling leaf development, EMBO J. 17 (1998) 170-180.

[4] Borralho N.M.G., Wilson P.J., Inheritance of initial survival and rooting ability in Eucalyptus globulus Labill. stem cuttings, Silvae Genet. 43 (1994) 238-242.

[5] Box G.E.P., Cox D.R., An analysis of transformation, J. Amer. Stat. Assoc. 39 (1964) 357-365.

[6] Bradshaw H.D., Foster G.S., Marker-aided selection and propagation systems in trees: advantages of cloning for studying quantitative inheritance, Can. J. For. Res. 22 (1992) 1044-1049.

[7] Brendel O., Pot D., Plomion C., Rozenberg P., Guehl J.M., Genetic parameters an QTL analysis of $\mathrm{d} 13 \mathrm{C}$ and ring width in maritime pine, Plant Cell. Environ. 25 (2002) 945-953.

[8] Britvin E., Minkov D., Glikson L., Ronin Y., Korol A., MultiQtl, an interactive package for genetic mapping of correlated quantitative trait complexes in multiple environments, version 2.0 (Demo). Plant \& Animal Genome IX, San Diego, CA, Abstract C01_01.html, 2001.

[9] Broman K.W., Review of statistical methods for QTL mapping in experiment crosses, Lab. Animal 30 (2001) 44-52.

[10] Cervera M.T., Plomion C., Malpica C., Molecular markers and genome mapping in woody plants, in: Jain S.M., Minocha S.C. (Eds.), Molecular Biology of Woody Plants, Kluwer Academic Publishers, The Netherlands, Forestry Sciences, Vol. 64, 1999, pp. 375-394.

[11] Churchill G.A., Doerge R.W., Empirical threshold values for quantitative trait mapping, Genetics 138 (1994) 963-971.

[12] Curir P., Van Sumere C.F., Termini A., Barche P., Marchesini A., Dolci M., Flavonoid accumulation is correlated with adventitious 
root formation in Eucalyptus dunnii Hook micropagation through axillary bud stimulation, Plant Physiol. 92 (1990) 1148-1153.

[13] Delarue M., Prinsen E., Van Onckelen H., Caboche M., Bellini C., Sur2 mutations of Arabidopsis thaliana define a new locus involved in the control of auxin homeostasis, Plant J. 14 (1998) 603-611.

[14] Falconer D.S., Mackay T.F.C., Introduction to Quantitative genetics, 4th ed., Longman Scientific \& Technical, New York, 1996.

[15] Frewen B.E., Chen T., Howe G.T., Davis J., Rohde A., Boerjan W., Bradshaw H.D., Quantitative trait loci and candidate gene mapping of bud set and bud flush in Populus, Genetics 154 (2000) 837-845.

[16] Geldermann H., Investigations on inheritance of quantitative characters in animals by gene markers. I. Methods, Theor. Appl. Genet. 46 (1975) 319-330.

[17] Grattapaglia D., Sederoff R., Genetic linkage maps of Eucalyptus grandis and E. urophylla using a pseudo-testcross mapping strategy and RAPD markers, Genetics 137 (1994) 1121-1137.

[18] Grattapaglia D., Bertolucci F.L., Sederoff R.R., Genetic mapping of quantitative trait loci (QTLs) controlling vegetative propagation in Eucalyptus grandis and E. urophylla, using the pseudo-testcross mapping strategy and RAPD markers, Theor. Appl. Genet. 90 (1995) 933-947.

[19] Han K.H., Bradshaw H.D., Gordon M.P., Adventitious root and shoot regeneration in vitro is under major gene control in an $F_{2}$ family of hybrid poplar (Populus trichocarpa $\times$ P. deltoides), For. Genet. 1 (1994) 139-146.

[20] Hartmann H.T., Kester D.E., Davis F.T., Plant propagation: principles and practices, Prentice Hall, Englewood Cliffs, N.J, 1990.

[21] Jansen R.C., Stam P., High resolution of quantitative traits into multiple loci via interval mapping, Genetics 136 (1994) 14471455 .
[22] Lin Y.R., Shertz K.F., Paterson A.H., Comparative analysis of QTLs affecting plant height and maturity across the Poaceae, in reference to an interspecific Sorghum population, Genetics 141 (1995) 391-411.

[23] Liu B.H., Reid D.M., Auxin and ethylene-stimulated adventitious rooting in relation to tissue sensibility to auxin and ethylene production in sunflower hypocotyls, J. Exp. Bot. 43 (1992) 1191-1198.

[24] Marques C.M., Vasquez K.J., Carocha V.J., Ferreira J.G., O’Malley D.M., Liu B.H, Sederoff R.R., Genetic dissection of vegetative propagation traits in Eucalyptus tereticornis and E. globules, Theor. Appl. Genet. 99 (1999) 936-946.

[25] Plomion C., Durel C.E., O'Malley D., Genetic dissection of height in maritime pine seedlings raised under accelerated growth conditions, Theor. Appl. Genet. 93 (1996) 849-858.

[26] Plomion C., Bahrman N., Durel C.E., O'Malley D.M., Genomic analysis in Pinus pinaster (maritime pine) using RAPD and protein markers, Heredity 74 (1995) 661-668.

[27] Saintagne C., Bodénès C., Barreneche T., Pot D., Plomion C., Kremer A., Distribution of genomic regions differentiating oak species assessed by QTL detection, Heredity 92 (2004) 20-30.

[28] Sewell M.M., Neale D.B., Mapping quantitative traits in forest trees, in: Jain S.M., Minocha S.C. (Eds.), Molecular Biology of Woody Plants, Kluwer Academic Publishers, The Netherlands, Forestry Sciences, Vol. 64, 1999, pp. 407-423

[29] Tsarouhas V., Gullberg U., Lagercrantz U., An AFLP and RFLP linkage map and quantitative trait locus (QTL) analysis of growth traits in Salix, Theor. Appl. Genet. 105 (2002) 277-288.

[30] Voorrips R.E., MapChart version 2.0: Windows software for the graphical presentation of linkage maps and QTLs, Plant Research International, Wageningen, The Netherlands, 2001.

[31] Zeng Z.B., Precise mapping of quantitative trait loci, Genetics 136 (1994) 1457-1468. 